\title{
DA REPRESENTAÇÃO AO SENTIDO ATRAVÉS DE SCHLEIERMACHER À HERMENÊUTICA ATUAL
}

Aloísio Ruedell

SINTESE - Este artigo traz resumidamente a discussão de uma tese de doutorado, centrada, fundamentalmente, no projeto hermenêutico de Friedrich Schleiermacher e situa-se, num contexto mais amplo, no hodiemo debate das alternativas para a filosofia. A contribuição e a importância da discussão consistem, entretanto, em participar de uma releitura do pensamento de Schleiermacher, visando a recuperação de seu aspecto sistemático.

PALAVRAS-CHAVE - Representação. Sentido. Hermenêutica. Linguagem. Interpretação psicológica. Interpretação gramatical.
ABSTRACT - This article outlines the relationship between the theoretical production on $\mathrm{M}$. Dufrennes's aesthetics and Husserl's phenomenological legacy, starting from a study of the Phénoménologie de l'Expénience esthétique.

KEY WORDS - Representation. Meaning. Hermeneutic. Language. Psychological interpretation. Grammatical interpretation.

Este título indica o tema e, ao mesmo tempo, também fornece o contexto em que foi desenvolvida uma tese de doutorado em filosofia, da qual se pretende fazer aqui uma breve apresentação. Centra-se ela, fundamentalmente, na discussão do projeto hermenêutico de Friedrich Schleiermacher. A novidade e a importância dessa discussão consistem, entretanto, em participar de uma releitura desse autor, liderada, na Alemanha, por Manfred Frank. Assume a recuperação do aspecto sistemático do pensamento de Schleiermacher, quase sempre minimizado ou ignorado pela recepção. Com esse procedimento, há uma efetiva integração no atual debate hermenêutico, onde se verifica um sempre maior diálogo com as ciências, particularmente ciências da linguagem. É nessa perspectiva que se entende a indagação por uma conciliação entre a análise estrutural do texto e a interpretação de seu sentido, presente em todo desenvolvimento da tese, mas especialmente trabalhada no último capítulo.

Doutor em Filosofia pela PUCRS. 
No entanto, para além de seu contexto mais imediato da hermenêutica, a discussão situa-se também no contexto mais amplo de toda filosofia. Integra, de alguma forma, o hodierno debate sobre a questão das alternativas para a filosofia, visando superar o pensamento tradicional, entendido como representação e, ao longo da História, sustentado a partir da relação sujeito-objeto. Participa das posições filosóficas que se estabelecem a partir da linguagem e que rejeitam ou que se sobrepõem ao caráter ontológico do pensamento ocidental, sobretudo ao que se constitui a partir do objeto.

A proposição da linguagem como caminho filosófico alternativo, contudo, ainda não basta para uma caracterização adequada do cenário filosófico em que se insere a tese. Há, pois, perspectivas e concepções diferenciadas da linguagem, donde resulta que a própria palavra altemativa também seja entendida de maneira diversa. São ao menos duas as principais perspectivas ou correntes filosóficas, constituindo-se em visões de linguagem distintas, a da analítica e a da hemenêutica. Quando, por isso, se trata da superação ou sobreposição da ontologia pela linguagem, oferece-se, em todo caso, uma dupla possibilidade. A investigação da tese aqui apresentada segue a linha da filosofia hermenêutica. Enquanto tal, reconhece, à semelhança da analítica, a importância fundamental da linguagem e mantém a crítica ao primado ontológico. A linguagem é, para ela, o único acesso à realidade, mas a irredutibilidade do ser a suas expressões lingüísticas exige não apenas análise como também a interpretação da linguagem. Por isso, a proposição da hermenêutica como caminho filosófico alternativo, com vistas à superação do caráter ontológico do pensamento, não tem um sentido absoluto. Embora se entenda como alternativa, ela é apresentada como ainda sempre vinculada à representação e à filosofia da subjetividade. Trata, pois - como diz o título - da passagem da representação ao sentido, onde o acento da tematização permanece na passagem. Pretende-se verificar como ela se caracteriza no pensamento hermenêutico de Schleiermacher, hoje reapresentado e valorizado em virtude de sua releitura.

Considerando, porém, a amplitude e a complexidade do tema, a discussão também não deixa de valorizar contribuições importantes de outros autores, tais como Paul Ricoeur. A sua referência é, contudo, mais pontual, sem a pretensão de confrontar com seu pensamento todas as questões da tese. É especialmente lembrado por suas discussões entre a hermenêutica e as ciências, especialmente as ciências da linguagem e a psicanálise. De modo semelhante, considerando o caráter dialógico da concepção hermenêutica aqui defendida, não faltam discussões sobre a filosofia analítica da linguagem. Isso é decisivo na medida que hoje se reconhece, que a relação entre as posições analítica e hermenêutica não é mais tanto de oposição quanto de distinção e de complementaridade. Ao mesmo tempo que a hermenêutica necessita da analítica, em vista de sua própria inteligibilidade, a discussão analítica complementa-se pelo conteúdo da hermenêutica. ${ }^{1}$ Outra

1 Cf. Ineichen (1991) 275. 
questão, que acompanha e, em parte, já precede à discussão proposta, é a contextualização histórica da hermenêutica de Schleiermacher. Que concepções e atividades hermenêuticas terão servido de ponto de partida para as suas discusssões? Como e por que ele terá sido desafiado a elaborar um novo projeto hermenêutico, dando origem a uma tradição de pensamento que se estende até os nossos dias? Tudo isso, ainda num sentido de contextualização - agora não tanto de Schleiermacher, mas sobretudo da tese discutida - é precedido por um esclarecimento terminológico. Este vem a ser uma necessidade diante da evolução do conceito de hermenêutica e, sobretudo, por causa da confusão no emprego do termo ou de termos semelhantes.

\section{II}

Essas considerações mais gerais sobre a proposição da tese já fornecem um quadro bastante aproximado do que é o seu desdobramento. Ela é desenvolvida ao longo de quatro capítulos, contendo cada qual uma idéia fundamental distinta. O primeiro capítulo, conforme já referido, tem um caráter mais introdutório, constituindo-se de um esclarecimento terminológico (distinção entre hermenêutica técnica, hermenêutica filosófica e filosofia hermenêtica) e de uma contextualização desta discussão e, sobretudo, do próprio pensamento hermenêutico de Schleiermacher. Já o segundo capítulo - A fundamentação teórico-subjetiva da interpretação - está especialmente marcado pela vinculação que a hermenêutica ainda mantém com as teorias da consciência e a filosofia da subjetividade em geral. Evidencia-se aí que a hermenêutica vive da subjetividade e como esta, contudo, não se constitui em ponto de partida filosófico adequado. Hermenêutica, verdade $e$ linguagem é o tema do terceiro capítulo. Ele tem basicamente duas preocupações: 1. mostrar a função fundamental da linguagem no processo do conhecimento e, de modo particular, na pretensão de verdade dos enunciados assertóricos; 2 . apresentar sistematicamente diversas concepções de linguagem, particularmente a teoria da linguagem hermenêutica de Schleiermacher, para, ao final, concluir com uma análise das perspectivas hermenêuticas que daí resultam. O quarto e último capítulo, juntamente com a conclusão, contêm mais fortemente o próprio objetivo da tese: demonstrar como na hermenêutica de Schleiermacher se abre uma perspectiva de diálogo entre as ciências da linguagem e a interpretação de sentido. Há uma especial visibilização deste caráter quando, no contexto da interpretação psicológica, se examina o teorema da divinação. Neste conceito, com o desafio de refazer, de alguma forma, a criatividade e o estilo do autor, requer-se igualmente um procedimento criativo e produtivo na interpretação. No entanto, a liberdade e a criatividade do intérprete, mesmo que não se reduzam à lógica semântica, somente são possíveis nos estreitos limites da linguagem. Os limites da interpretação e da compreensão aí encontrados são os próprios limites do entendimento humano. 
Até aqui, pode-se dizer, a discussão desenvolvida na tese já está suficientemente apresentada. Convém, contudo, ainda destacar e expor de maneira mais sistemática as principais subteses sustentadas ao longo do texto. Mas, com a proposição dessa tarefa, não se entende que teses, no plural, tenha algo a ver com uma possivel fragmentação da discussão. Trata-se, antes, de diversos aspectos e desdobramentos ou figuras de uma mesma e única tese, construída em torno da pergunta por uma conciliação entre as ciências da linguagem e a interpretação de sentido. É a perspectiva que acompanha todo o desenvolvimento da pequisa, tendo, contudo, seu ponto alto no último capítulo. Todos os temas e conceitos discutidos estão marcados por uma dupla característica. Por um lado, é a linguagem, enquanto sistema - objeto próprio das ciências e da filosofia analítica - que permite a sua discussão. É ela, único acesso possível, o limite e, sobretudo, a condição indispensável para a sua compreensão. Mas, reconhecer na linguagem a conditio sine qua non não quer dizer que ela também seja a ratio per quam. Ao contrário, o próprio estabelecimento da linguagem, bem como sua manutenção e seu desenvolvimento só se esclarecem à luz de seu discurso instituinte, mediante o concurso de projetos singulares de sentido. Embora sempre nos estreitos limites e condições da linguagem, é na esfera subjetiva da consciência dos indivíduos que se estabelece e se compreende todo sentido. Há uma transcendência do ser em relação ao sentido, que, além da análise, exige também a interpretação da linguagem.

A identificação dessa dupla perspectiva no pensamento de Schleiermacher, vinculada à sua releitura, confere-lhe um caráter de atualidade, para o hodierno debate hermenêutico, e justifica a sua discussão. Sua tese é que nenhum aspecto existe isoladamente. Nega, à linguagem, tanto a autonomia de seu caráter sistemático-científico quanto de sua instituição e aplicação sempre singularizadas. Sem dizer, que não possa haver predominância de um dos aspectos, cada qual sempre ocorre como síntese com o outro.

Importa, agora, ver como se caracteriza, nos mais diversos momentos da discussão, esse diálogo entre a perspectiva das ciências e a da hermenêutica. Para facilitar o acompanhamento e a compreensão do raciocínio, os aspectos ou teses a serem referidos serão identificados por enumeração.

1. Participar do debate hodierno sobre as alternativas para a filosofia - que é o propósito desta tese - põe, antes de mais nada a questão da linguagem. Qual é a sua concepção? Em toda discussão desenvolvida e no próprio pensamento de Schleiermacher identifica-se nela uma dupla característica. Como o pensamento, assim também a dinâmica da linguagem comporta um elemento lógico-racional e outro interpretativo, abrigando - na terminologia de Heidegger - tanto um logos apofântico quanto hermenêutico. Consiste na interação de duas funções, que apenas se distinguem pela predominância de uma ou de outra e que não podem ser 
consideradas isoladamente, sob pena de resultar em concepções abstratas. ${ }^{2}$ Tanto não existe, por um lado, uma estrutura como um aparato fixo, a partir do qual se daria o uso particular da linguagem, como também não se trata de uma simples junção de vagas instituições de sentido, que poderiam estar tanto de um quanto de outro lado da corrente verbal. Todo discurso humano é, na verdade, sempre as duas coisas: estrutura e sentido. Ou, como também diz Heinz Kimmerle, ao tratar da relação entre hermenêutica e ciências do espírito: em toda ciência há sempre uma dupla pressuposição: histórico-subjetiva e singular e sistemático-universal. ${ }^{3}$

2. Essa dupla concepção da linguagem é especialmente tematizada na discussão entre dialética e hermenêutica. Com a superação do primado ontológico, impõe-se, para Schleiermacher, uma razão discursiva, que é o seu entendimento da dialética. Enquanto arte de se entender ou dialogar, ${ }^{4}$ ela garante a vinculação com a linguagem e é, na verdade, a ciência filosófica superior, à qual está submetida a hermenêutica. É uma necessidade que se impõe em vista do saber e diante da impossibilidade de se obtê-lo plenamente. ${ }^{5}$ Devido à limitação humana, ${ }^{6}$ e em não existindo um ponto arquimédico, donde se pudesse avaliar os conhecimentos progressivamente logrados, precisa-se admitir, acredita Schleiermacher, que nunca faltará motivo de discussão. A saída é a conversação, o diálogo intersubjetivo. Com a superação do sujeito, sem condições de uma busca solitária da verdade e não havendo mais um princípio metafísico regulador, é essa a única maneira de se chegar a verdades comuns e, tanto quanto possível, livres de conflito.

O princípio da dialética está estreitamente vinculado à universalização da não-compreensão ou dos mal-entendidos, donde parte a hermenêutica. Se a compreensão, como diz Schleiermacher, nunca se dá por si, mas precisa ser buscada, essa busca não se pode confundir com um procedimento solitário ou monólogo. A hermenêutica, enquanto "arte de compreender corretamente o discurso [...] de outrem", participa de uma busca dialógica do saber. Não há, pois, conhecimento ou saber que não se estabeleça pela linguagem, pressupondo, para a sua constituição, uma "comunidade lingüística" e de "conhecimento" - donde a necessidade e a função da dialética, garantindo o caráter sistemático e comunitário do saber. É, entretanto, a manifestação sempre singular do saber, sua realização em linguagens e modos de ser particulares, que exige a presença da hørmenêutica. Enquanto a dialética especulativa permite a compreensão da identidade racional, no pen-

\footnotetext{
Cf. Schleiermacher (1990) 25.

Gerber (1971) 29.

Cf. Schleiermacher (1942) 5.

Cf. Schleiermacher (1942) 7.

Caberia aqui todo um capítulo sobre a teoria do sujeito de Schleiermacher, que está na base de toda a sua concepção de linguagem e de hermenêutica. Por mais que ele destaque a subjetividade singular para a constituição e a compreensão do sentido, está longe de lhe atribuir o caráter absoluto e de auto-suficiência encontrado em Descartes. Ao contrário, para ele o sujeito é dependente e limitado, não se constituindo em ponto de partida filosófico adequado. $\mathrm{O}$ sujeito apenas emerge como termo de relação, nunca podendo ser flagrado na pureza de sua identidade. Na sua concepção de sujeito, frágil e dependente, é impensável qualquer psicologismo.

7 Schleiermacher (1990) 71.
} 
samento e na comunicação lingüística, a hermenêutica, seguindo caminhos e métodos próprios, procura reconstruir o discurso lingüisticamente singular e conhecer o pensamento nele contido. Resumidamente, arte hermenêutica "é dissolução da linguagem no pensamento; dialética é [...] dissolução do pensamento na linguagem". ${ }^{8}$ A hermenêutica é, em certo sentido, o inverso da dialética, como também 0 ato de compreensão é o inverso do ato de discurso. ${ }^{\circ}$ Mas, estando 0 processo de conhecimento, enquanto intercâmbio de pensamentos, vinculado à comunicação e à compreensão, hermenêutica e dialética exigem-se mutuamente; uma depende da outra. Complementam-se numa "perfeita interação", e é isso que se desenvolve e evidencia sempre mais no próprio pensamento. ${ }^{10}$

3. Talvez o aspecto mais presente ao longo do texto e identificado no pensamento de Schleiermacher seja o da questão transcendental. Reconhece-se que, à semelhança do giro copernicano de Kant, notadamente crítica da razão e do conhecimento, há, em Schleiermacher, o giro transcendental no mundo do sentido e da compreensão. Para além de sua preocupação técnica em resolver um problema de interpretação e compreensão, tinha ele a pergunta fundamental por suas condições de possibilidade. A novidade e a contribuição nessa questão - além de submeter o aspecto do conhecimento ao do sentido - está na identificação de uma dupla condição, a consciência subjetiva e a linguagem. Por um lado, é à luz da consciência livre do sujeito que, segundo Schleiermacher, se esclarece a questão do sentido. O caráter subjetivo é, para ele, condição de possibilidade, não só da compreensão, mas do próprio estabelecimento do sentido. Na base de todo discurso e da linguagem, enquanto sistema, há um projeto singular de sentido somente inteligivel à luz da subjetividade. Essa é, sem dúvida, uma idéia fundamental da hermenêutica de Schleiermacher e que, por isso, também está presente ao longo de toda a discussão da tese. Recebe ainda um destaque especial no capítulo II, Fundamentação teórico-subjetiva da interpretação, e nas abordagens sobre a interpretação técnica e psicológica.

O aspecto da subjetividade é, contudo, apenas uma das condições do sentido. Ao mesmo tempo que o sujeito, livre e criativo, possibilita seu estabelecimento e sua compreensão, é somente na e pela linguagem que ele pode ser projetado e compreendido. Não há pensamento ou projeto que já não tenha sempre a forma da linguagem, no sentido de que todo pensar "já é um falar interior", valendo-se de recursos lingüísticos. $\mathrm{E}$ a própria consciência de si não dispõe de si mesma, na pureza de sua identidade, mas somente como elemento de relação, onde as formas da relação são as da linguagem. Nisto está, sem dúvida, uma novidade: são duas as condições básicas que possibilitam a compreensão do sentido, a consciência subjetiva e a linguagem. Há, efetivamente, em Schleiermacher, uma dialética entre a crítica e a valorização da consciência de si e de seus desdobramentos. É uma posição que, de alguma forma, prenuncia aquilo que hoje muitos filósofos

Dial J 260, citado em Scholtz (1984) 147.

Cf. Schleiermacher (1974) 76.

Cf. Scholtz (1984) 147 e também Schleiermacher (1990) 30. 
caracterizam como "processo de retranscendentalização, que talvez significa a recuperação da questão transcendental no percurso da crítica". ${ }^{11}$ Se antes a questão estava exclusivamente vinculada à autoconsciência, hoje a própria consciência se amplia e recoloca no âmbito da linguagem.

4. Correspondendo à concepção da linguagem e à dupla condição de possibilidade do sentido, encontram-se, em Schleiermacher, também duas perspectivas de interpretação, psicológica e gramatical, podendo a primeira ainda ser desdobrada em técnica. Um discurso é objeto da interpretação psicológica quando abordado do ponto de vista de sua gênese, ou seja, a partir do contexto de seu autor. Fora, sem dúvida, este o desafio fundamental de Schleiermacher: entender o outro, o diferente; entendê-lo em sua singularidade subjetiva. Por isso, para entender um discurso, é preciso interpretá-lo nesta perspectiva - que é a perspectiva psicológica - enquanto marcado pela peculiaridade de seu autor ou falante. Este tomase, de alguma forma, critério de interpretação. A hermenêutica, enquanto arte de interpretação e de compreensão, privilegia a gênese e a recepção do discurso. É daí que este tem o seu sentido, da consciência que o projeta e compreende. Por mais que ele dependa de certas regras de linguagem, estas, embora condição de possibilidade, não são sua causa per quam, e até mesmo só se esclarecem a posteriori, como post festum, ${ }^{12}$ depois de estabelecidas e aplicadas pela comunidade lingüística. A própria racionalidade é, dessa maneira, remetida à sua origem, porque a revelação do sentido sempre é uma compreensão do sujeito, realiza-se numa consciência subjetiva. Radicalizando, sustenta-se inclusive em Schleiermacher, que o universal enquanto tal não existe, ao menos não sem o concurso de projetos individuais. ${ }^{13} \mathrm{~A}$ dimensão individual e subjetiva é essencial, tanto na compreensão quanto no estabelecimento de um sentido.

Se, no entanto, o desafio principal, na interpretação de um texto, é refazer o pensamento interior do autor e o processo de sua elaboração, não se pode, contudo, esquecer, que o próprio pensamento é uma fala, uma "fala interior", ${ }^{14}$ como diz Schleiermacher. Não existe primeiro um puro pensar, e depois a sua comunicação. Já sempre se pensa em termos ou palavras e segundo regras gramaticais. No ato de pensar, por mais interior e particular que possa ser, está sempre pressuposto 0 aparato da linguagem, objetiva e sistematicamente constituída. Por isso, compreender um discurso é compreendê-lo nestas duas perspectivas, "como extraído da linguagem" e "enquanto fato daquele que pensa". ${ }^{15}$ Numa requer-se a "interpretação gramatical" e noutra a "psicológica", considerando o discurso, respectivamente, como um dado da língua e como expressão do autor ou falante. Toda compreensão é sempre, ao mesmo tempo, "gramatical" e "psicológica". Nenhum dos dois aspectos pode estar ausente quando há efetiva compreensão, nem se pode dizer

\footnotetext{
Stein e De Boni (1993) 91.

Cf. Schleiermacher (1990) 23.

Cf. Schleiermacher (1990) 18.

Schleiermacher (1942) 9.

Schleiermacher (1990) 77.
} 
que um é mais importante do que o outro, ainda que o destaque possa ser diverso, conforme o enfoque que se pretenda dar. "Seria ilegítimo - afirma literalmente Schleiermacher - dizer que a interpretação gramatical é inferior e que a psicológica é superior". ${ }^{16}$

5. O que está na base da interação dialética entre as diversas perspectivas de interpretação é o círculo hermenêutico, assim denominado, presente em todo procedimento interpretativo. Qual é a sua concepção? Seria esse círculo apenas negativo e, segundo as regras da lógica, sempre vicioso, mesmo nas ciências do espínto? Neste caso, deveria ser evitado, ou então dever-se-ia manter o conhecimento menos rigoroso e, como conseqüência, ter-se-ia a impossibilidade da hermenêutica, sempre circular.

Heidegger, entretanto, demonstra como isso seria um procedimento equivocado: "[...] ver nesse círculo um vício, buscar caminhos para evitá-lo e também 'senti-lo' apenas como imperfeição inevitável, significa um mal-entendido de princípio acerca do que é compreensão". ${ }^{17}$ Não se trata de competir com um conhecimento ideal e rigorosamente científico, que, em verdade, já degenerou em incompreensão. A indagação pela compreensão e interpretação é mais profunda: visa as próprias condições de possibilidade do conhecimento, a circularidade hermenêutica, já sempre posta como ponto de partida para um procedimento veritativo. Por isso, se a interpretação não pode desconhecer sua condição de realização, "o decisivo não é sair do círculo, mas entrar nele corretamente" ${ }^{18} \mathrm{O}$ "círculo da compreensão - diz Heidegger - não é um cerco em que se movimenta qualquer tipo de conhecimento". É, isto sim, "a expressão da estrutura-prévia existencial do próprio Dasein", não podendo ser rebaixado a "círculo vicioso", porque abriga em si "a possibilidade positiva do conhecimento mais originário".

Já o projeto de Schleiermacher apontava, de alguma forma, para o sentido estrutural do círculo hermenêutico, demonstrando a complementaridade fundamental entre os aspectos particular e universal de uma interpretação. Qualquer uma das duas perspectivas hermenêuticas, argumenta ele, degenera em abstração quando não complementada pela outra: o particular só pode ser compreendido a partir do todo (universal) e o todo somente a partir do particular, ${ }^{20}$ porque um existe como síntese com o outro. A origem do círculo está na "dependência mútua entre os aspectos gramatical e psicológico, objetivo e subjetivo". E é também ai, na conjugação dos dois, que está a sua universalidade e se desenha todo o quadro do método interpretativo. Nenhum procedimento hermenêutico seria possível sem essa complementaridade. ${ }^{21}$

Com o círculo hermenêutico, que, por ser hermenêutico, sempre permanece aberto, pode-se dar por encerrada essa exposição de teses. Antes de concluir,

16 Schleiermacher (1990) 79.

17 Heidegger (1993) 153.

18 Heidegger (1993) 153.

19 Heidegger (1993) 153.

20 Cf. Schleiermacher (1974) 141-142.

21 Cf. Schleiermacher (1974) 141-142. 
cabe, contudo, ainda uma observação fundamental sobre o propósito específico de toda discussão, centrada na recuperação do caráter sistemático do pensamento de Schleiermacher, com vistas ao diálogo entre as ciências da linguagem e a hermenêutica. Reconhecer que, em Schleiermacher, a hermenêutica efetivamente se habilita para esse diálogo, não equivale a conferir-lhe também a certeza e o rigor científicos. Trata-se, pois, de enfoques e de campos de atuação diversos. Um constitui-se em torno de racionalidades comuns, outro, enquanto teoria da interpretação, indaga pelo singular e diferente de cada discurso. Segue perguntando por aquilo que ainda permanece distante e incompreendido, para além de todos os procedimentos analíticos. A pergunta pela possibilidade da compreensão e interpretação é, em Schleiermacher, efetivamente uma pergunta hermenêutica, no sentido de visar o outro e diferente, acreditando que todo texto ou discurso é diferente ou peculiar, em virtude da peculiaridade de seu autor.

A pergunta hermenêutica adquire, contudo, aí, um caráter especialmente desafiador, porque o outro, a quem ela visa, mesmo que não se reduza a conceitos lógico-semânticos, só pode ser entendido pela linguagem. O momento alto dessa discussão encontra-se no último capítulo, onde, na perspectiva da interpretação psicológica, se examina o teorema da divinação. Na sua concepção, com o desafio de refazer, de alguma forma, a criatividade e o estilo do autor, requer-se igualmente um procedimento criativo e produtivo na interpretação. No entanto, a liberdade e a criatividade do intérprete, mesmo que não se reduza à lógica semântica, somente é possível nos estreitos limites da linguagem. Os limites da interpretação e da compreensão aí encontrados são os próprios limites do entendimento humano.

A realização de uma discussão sobre o pensamento hermenêutico de Schleiermacher pode, hoje, receber críticas motivadas por razões históricas. Sua concepção de linguagem, obviamente, ainda carece de elementos filosóficolingüísticos, apenas obtidos posteriormente pela filosofia, especialmente neste século, quando todo pensamento passa a operar sob o viés da linguagem. Sua discussão, por isso, não seria adequada para a atualidade. Mas, se essa ressalva histórica, dum lado, poderia ser motivo para a desqualificação de seu pensamento, pode, contudo, também ser um desafio para nele já encontrar o projeto do que hoje está sendo discutido. Isso, sobretudo, vale pela recuperação do caráter sistemático de sua concepção hermenêutica.

\section{Referências bibliográficas}

FRANK, Manfred. Das individuelle Allgemeine; Textstrukturierung und - interpretation nach Schleiermacher. Frankfurt a.Main: Suhrkamp, 1977.

GERBER, Uwe (Hrsg.) Hermeneutik als Kriterium für Wissenschaftlichkeit?; Der Standort der Hermeneutik im gegenwärtigen Wissenschaftskanon; Dokumente des Kolloquiums vom Oktober 1971 (Loccumer Kolloquien 2). [Tübingen]: Loccum, 1972.

HEIDEGGER, M. Ser e Tempo - I. 3. ed. Tradução de Márcia de Sá Cavalcante. Petrópolis: Vozes, 1989.

Ser e Tempo - II. 2. ed. Tradução de Márcia de Sá Cavalcante. Petrópolis: Vozes, 1990.

Sein und Zeit. 17. Aufl. Tübingen: Max Niemeyer Verlag, 1993.

INEICHEN, Hans. Philosophische Hermeneutik. Freiburg/München: Karl Alber, 1991. 
RODI, Frithjof (Hrsg.). Dilthey Jahrbuch für Philosophie u. Geschichte der Geisteswissenschaften, Bd.8. Göttingen: Vande Twenty-two points, plus triple-word-score, plus fifty points for using all my letters. Game's over. I'm outta here.nhoeck \& Ruprecht 1992/93.

RODI, Frithjof. Erkenntnis des Erkannten; zur Hermeneutik des 19. und 20. Jahrhunderts. Frankfurt a. Main: Suhrkamp 1990.

SCHLEIERMACHER, Friedrich D.E. Dialektik. Im Auftrage der Preussischen Akademie der Wissenschaften auf Grund bisher unveröffentlichten Materials hrsg. von Rudolf Odebrecht. Leipzig: Henrichs Verlag, 1942.

Hermeneutik und Kritik; mit einem Anhang sprachphilosophischer Texte Schleiermachers. Hrsg. und eingeleitet von Manfred Frank, 4. Aufl. Frankfurt a. Main: Suhrkamp, 1990.

. Hermeneutik. Nach den Handschriften neu hrsg. und eingeleitet von Heinz Kimmerle. 2. verb. u. erweiterte Aufl. Heidelberg: Carl Winter Universitätsverlag, 1974.

. Hermenêutica: Arte e técnica da interpretação. Tradução e apresentação de Celso Reni Braida. Petrópolis: Vozes, 1999.

SCHOLTZ, Gunter. Die Philosophie Schleiermachers (Erträge der Forschung - 217). Darmstadt: Wissenschaftliche Buchgesellschaft, 1984.

STEIN, Emildo. Crítica da Ideologia e Racionalidade. Porto Alegre: Movimento, 1986.

. Seminário sobre a verdade; Lições preliminares sobre o parágrafo 44 de Sein und Zeit. Petrópolis: Vozes, 1993.

—. Aproximações sobre Hermenêutica. Porto Alegre: EDIPUCRS, 1996.

STEIN, Ernildo e DE BONI, Luís A. (org.) Dialética e Liberdade: Festschrift em homenagem a Carlos Roberto Cime Lima. Petrópolis, RJ: Vozes; PortoAlegre: Ed. da Universidade, 1993.

TUGENDHAT, Emst. Selbstbewusstsein und Selbstbestimmung; Sprachanalytische Interpretationen. 4. Aufl. - Frankfurt a. Main: Suhrkamp, 1979.

Vorlesungen zur Einführung in die sprachanalytische Philosophie. 5. Aufl. Frankfurt a. Main: Suhrkamp, 1990. 